\title{
Mitos Keris dalam Novel Hunus Karya Sunaryono Basuki Ks
}

\author{
Sri Septi Dwi Jayanti Putri ${ }^{1^{*},}$ Maria Matildis Banda ${ }^{2,}$ Sri Jumadiah $^{3}$ \\ ${ }^{[123]}$ Program Studi Sastra Indonesia, Fakultas Ilmu Budaya-Universitas Udayana \\ ${ }^{1}$ [dwijayantiputri5995@gmail.com], ${ }^{2}$ [mbanda574@gmail.com], \\ 3 [srijumadiah@gmail.com] \\ *Corresponding Author
}

\begin{abstract}
Abstrak
Objek penelitian ini adalah novel Hunus karya Sunaryono Basuki Ks. Novel Hunus dianalisis dengan menggunakan teori struktur dan teori sosiologi sastra. Penggunaan teori sosiologi sastra dalam penelitian ini tepat karena novel Hunus memiliki gambaran sosial yang kuat tentang kepercayaan tradisional tentang kesaktian keris. Rumusan masalah yang dibahas ialah struktur novel dan mitos keris dalam aspek budaya, agama, dan pendidikan yang terungkap dalam novel Hunus. Struktur novel Hunus, meliputi: alur, penokohan, dan latar. Alur novel Hunus menggunakan alur campuran. Penokohan dibagi menjadi tokoh utama dan tokoh tambahan, tokoh utama ialah Anthony Wright, tokoh tambahan yaitu Anak Agung Ngurah Ari Maharani, Wayan, Husni, Ida Bagus Sudiara. Kemudian latar tempat novel Hunus terjadi di Jakarta dan Inggris, latar waktu cerita novel sekitar tahun 1990-an, dan latar sosial menceritakan kehidupan masyarakat Bali. Mitos keris dalam novel Hunus difokuskan pada tiga aspek, yakni aspek budaya, agama, dan pendidikan. Aspek budaya membahas upacara tumpek landep. Dalam novel dijelaskan tata cara masyarakat Bali menyucikan benda pusaka dalam hal ini keris pada upacara tumpek landep. Aspek agama membicarakan latar belakang agama para tokoh mempercayai mitos keris. Tony dengan prinsip agama bersifat pribadi memandang mitos keris hanya suatu dongeng atau takhyul yang berlaku pada masyarakat yang memercayainya. Kemudian pikiran ini berubah ketika Tony mengalami kesaktian keris yang "membunuh" setiap kali dihunus. Sedangkan Gung Ari (istri Tony) beragama Hindu mempercayai mitos keris secara turun temurun baik berupa petuah maupun ritual tumpek landep yang harus diyakini. Aspek pendidikan membahas pendidikan yang didapatkan para tokoh mempengaruhi cara pandang terhadap mitos keris dalam konflik novel. Mendapatkan pendidikan formal yang sama, namun tokoh Gung Ari (istri Tony) memperoleh pendidikan informal dalam keluarganya mengenai mitos tentang keris. Mitos keris dalam novel Hunus mengajarkan bahwa kita harus menghargai setiap kepercayaan suatu masyarakat meskipun kita tidak lahir dan tumbuh dalam kepercayaan akan mitos tersebut.
\end{abstract}

Kata kunci : novel, sosiologi sastra, mitos keris

\begin{abstract}
The object of this study was the novel Hunus by Sunaryono Basuki Ks. The novel Hunus was analyzed by using theory of structure and theory of literature sociology. The using of theory of literature sociology in this study was proper because the novel Hunus had an intense social depiction of traditional belief about the supernatural power of kris. The problems of study discussed were the structure of the novel and the myth of kris within the aspects of culture, religion, and education that were revealed in the novel Hunus. The structure of the novel Hunus encompassed: plots, characterization, and backgrounds. The plots of the novel Hunus used the plot of mix. The characterization was divided into the main character and the additional characters, the main character was Anthony Wright, and the additional characters were Anak Agung Ngurah Ari Maharani, Wayan, Husni, and Ida Bagus Sudiara. The background of place happened in Jakarta and England, the background of time was in 1990's, and the background
\end{abstract}


of social told about the life of Balinese people. The myth of kris in the novel Hunus was focused on three aspects; they were the aspects of culture, religion, and education. The aspect of culture discussed about the ceremony of Tumpek Landep. In the novel, it was explained about the procedures of Balinese people in purifying heirlooms, in this case it was kris, on the ceremony of Tumpek Landep. The aspect of religion discussed about the religious background of the characters who believed in the myth of kris. Tony with his personal religious principle considered that the myth of kris was just a fairytale or superstition which only applied to the people who believed it. Meanwhile Gung Ari (Tony's wife) was Hindu that she believed in the myth of kris from generation to generation in the form of religious advice that had to be believed as customs which had existed in Balinese society. Then, his thought changed when he experienced the spiritual power of kris that "killed" everytime being impaled. Meanwhile Gung Ari (Tony's wife) was Hindu that she believed in the myth of kris from generation to generation in the form of spiritual advice or the ritual of Tumpek Landep that had to be believed. The aspect of education discussed about the education obtained by the religious characters that influenced the perspective towards the myth of kris that happened in the conflict of the novel. Getting the same formal education, but Gung Ari obtained an informal education from her family about the myth of kris. The myth of kris in the novel Hunus taught us that we must respect every faith in a society even though we were not born and grown in the belief of that myth.

Key words: novel, literature sociology, myth of kris

\section{Latar Belakang}

Folklor setengah lisan adalah folklor yang bentuknya merupakan campuran unsur lisan dan unsur bukan lisan, misalnya kepercayaan rakyat. Kepercayaan rakyat yang oleh orang barat (modern) seringkali disebut takhyul itu terdiri dari pernyataan yang bersifat lisan ditambah dengan gerakan isyarat yang dianggap mempunyai makna gaib, seperti tanda salib bagi orang Kristen Katolik yang dianggap dapat melindungi seseorang dari gangguan hantu atau ditambah dengan benda material, seperti batu-batu permata tertentu yang dianggap berkhasiat untuk melindungi diri atau membawa rezeki (Danandjaya, 1991: 22). Dalam suatu karya sastra tak jarang menceritakan mengenai kepercayaan tradisional masyarakat nusantara. Salah satu jenis karya sastra yaitu novel sering kali menceritakan mengenai kepercayaan tradisional. Novel yang menceritakan tentang kepercayaan tradisional kelompok masyarakat tertentu antara lain: Calon Arang karya Pramoedya Ananta Toer, Roro Mendut karya Y.B. Mangunwijaya, Ronggeng Dukuh Paruk karya Ahmad Tohari. Kepercayaan tradisional tersebut merupakan mitos yang diyakini kebenarannya dan menjadi bagian dari folklor setengah lisan.

Novel sebagai salah satu jenis karya sastra ditentukan oleh kreativitas dan pandangan dunia penulis yang diekspresikan melalui alur, latar, dan perwatakan. Sebagaimana yang dijelaskan Endraswara (2008:78), karya sastra merupakan wujud nyata imajinasi kreatif dari seorang sastrawan dengan proses yang berbeda-beda antara satu pengarang dengan pengarang lainnya, terutama dalam penciptaan cerita fiksi. Penciptaan tersebut bersifat individualistis dan berciri khas tertentu sesuai cara pandang pengarang tersebut. Meskipun demikian sastra juga hidup dan ada karena adanya fakta-fakta atau realitas-realitas di bumi yang ditangkap oleh pengarang sehingga dapat dikatakan bahwa sastra merupakan cerminan kehidupan. Karya sastra merupakan hasil ekspresi kehidupan manusia yang tidak akan lepas dari akar masyarakat (Endraswara, 2008:78). Salah satu novel yang bercerita mengenai masyarakat dalam hal ini kepercayaan tradisional adalah novel Hunus. 
Novel Hunus, karya Sunaryono Basuki Ks terbit tahun 1991, terdiri atas 205 halaman, mengisahkan seorang pria Inggris, Anthony Wright yang menjalin hubungan dengan gadis Bali, Anak Agung Ngurah Ari Maharani (Gung Ari). Mereka menjalin hubungan hingga jenjang pernikahan, walaupun tanpa restu orang tua Gung Ari. Setelah kelahiran buah hati mereka, Tony memutuskan untuk kembali ke Inggris menemui ibunya dan memperkenalkan Gung Ari pada tanah airnya. Kehidupan mereka berjalan lancar. Dalam kisah selanjutnya keluarga Anthony dilanda tragedi, yaitu dua orang sahabat, ibu, istri (Gung Ari), dan Cempaka (anak Anthony dan Gung Ari) meninggal secara misterius. Kematian berturut-turut itu terjadi setiap kali keris dihunus. Tampaknya mitos mengenai keris ini mengguncang Anthony yang selalu berpikir logis, berhadapan dengan keyakinan tradisional (mitos) bahwa kerislah yang menyebabkan kematian demi kematian itu. Novel Hunus membahasakan secara mendalam kepercayaan tradisional masyarakat tentang keris. Setiap kali keris dikeluarkan dan dihunuskan terjadi suatu "kematian". Hal inilah yang menjadikan mitos tentang keris lebih menakutkan dan menjadikan novel Hunus menarik untuk dikaji lebih lanjut.

Alasan novel Hunus dijadikan sebagai objek penelitian. Pertama, novel ini menggambarkan kepercayaan masyarakat Bali terhadap mitos keris. Kedua, novel Hunus menggambarkan romantika hubungan antara orang Bali dan orang asing. Hubungan ini menimbulkan proses interaksi sosial budaya Timur dan Barat yang terungkap melalui konflik tentang mitos keris. Ketiga, setelah dilacak dari berbagai sumber di internet, novel ini belum pernah diteliti dalam bentuk skripsi.

Novel Hunus membahasakan secara mendalam kepercayaan tradisional masyarakat tentang keris. Setiap kali keris dihunus terjadi suatu "kematian". Hal inilah yang menjadikan mitos tentang keris lebih menakutkan dan menjadikan novel Hunus menarik untuk dikaji lebih lanjut agar makna dari novel ini bisa terungkap.

\section{Pokok Permasalahan}

Berdasarkan latar belakang di atas terdapat dua pokok permasalahan yang dibahas dalam penelitian ini. Pertama, Bagaimanakah struktur novel Hunus yang meliputi unsur alur, penokohan, dan latar?; Kedua, Bagaimanakah mitos keris dalam aspek budaya, agama, dan pendidikan dalam novel Hunus?

\section{Tujuan Penelitian}

Tujuan umum yang hendak dicapai dalam penelitian ini adalah untuk menambah perbendaharaan penelitian sastra khususnya Sastra Indonesia. Secara khusus tujuan penelitian ini adalah, pertama, untuk mengetahui struktur novel Hunus. Kedua, mengetahui mitos keris dalam aspek budaya, agama, dan pendidikan dalam novel Hunus karya Sunaryono Basuki Ks

\section{Metode Penelitian}

Metode dan teknik penelitian dibagi menjadi tiga, yaitu: (1) Metode dan Teknik Pengumpulan Data. Pada tahapan pengumpulan data, metode yang digunakan adalah metode studi pustaka dengan teknik lanjutan berupa teknik catat atau tulis. Sumber tertulis terdiri atas buku, majalah ilmiah, arsip, dokumen pribadi, dan dokumen resmi (Moleong, 1990:113). Data utama dalam analisis ini adalah struktur dan aspek sosiologis terutama aspek budaya, agama, dan pendidikan yang terdapat dalam novel Hunus. Objek dibaca secara intensif dan berulang-ulang, kemudian dicatat data yang penting. Data sebagai penunjang analisis diperoleh dari buku- 
buku teori yang menunjang penelitian ini. (2) Metode dan Teknik Analisis Data. Dalam tahapan ini metode yang digunakan adalah metode formal dan metode deskriptif analisis. Metode formal adalah metode yang digunakan dalam analisis dengan mempertimbangkan aspek-aspek formal, aspek-aspek bentuk, yaitu unsur-unsur karya sastra (Ratna, 2007:49). Metode deskriptif analisis dilakukan dengan cara mendeskripsikan fakta-fakta yang kemudian disusul dengan analisis yang dapat dipertanggungjawabkan. Metode deskriptif tidak semata-mata menguraikan, melainkan juga memberikan pemahaman dan penjelasan secukupnya mengenai data yang ada (Ratna, 2007:53). Dalam pengolahan data dipergunakan teknik simak dan catat. Teknik simak dan catat merupakan lanjutan dari teknik membaca sebagai pengembangan terhadap pemahaman yang didapatkan dari proses membaca. (3) Metode dan Teknik Penyajian Hasil Analisis Data. Pada tahapan ini digunakan metode deskripsi, yakni dengan mendeskripsikan hasil analisis data yang telah dilakukan. Kemudian disusun ke dalam format penelitian berupa skripsi dengan menggunakan bahasa Indonesia ragam ilmiah. Data yang telah dikumpulkan, diolah, akhirnya disajikan. Penyajian hasil pengolahan data menggunakan sistematika sebagai berikut. Bab I berisi pendahuluan yang merupakan pengembangan rancangan penelitian yang dilaksanakan. Pendahuluan terdiri atas latar belakang, rumusan masalah, tujuan penelitian, manfaat penelitian, penelitian sebelumnya, landasan teori, serta metode dan teknik penelitian analisis data. Bab II berisi analisis struktural novel Hunus karya Sunaryono Basuki Ks. Analisis struktural terdiri atas alur, penokohan, dan latar. Bab III berisi analisis mitos keris dalam aspek budaya, agama, dan pendidikan dalam novel Hunus karya Sunaryono Basuki Ks. Bab IV merupakan penutup yang berisi simpulan dan saran.

\section{Hasil dan Pembahasan}

Analisis ini dapat disimpulkan bahwa, struktur novel Hunus karya Sunaryono Basuki Ks, yaitu: Alur dibagi menjadi tiga bagian, yaitu tahapan awal, tahapan tengah, dan tahapan akhir. (1) Tahapan awal sebuah cerita biasanya disebut sebagai tahapan perkenalan. Tahapan perkenalan pada umumnya berisi sejumlah informasi penting yang berkaitan dengan berbagai hal yang akan dikisahkan pada tahapan-tahapan berikutnya. Fungsi pokok tahapan awal sebuah cerita adalah untuk memberikan informasi dan penjelasan seperlunya. Khususnya yang berkaitan dengan dengan latar dan penokohan (Nurgiyantoro, 2005:142). (2) Tahapan tengah adalah inti cerita yang disajikan seperti: tokoh memainkan peran, peristiwa penting yang dikisahkan, konflik berkembang semakin meruncing, menegangkan, dan mencapai klimaks (Nurgiyantoro, 2015:145). (3) Tahapan akhir menampilkan adegan tertentu sebagai akibat klimaks. Jadi tahapan ini berisi bagaimana kesudahan cerita, atau menyarankan pada hal bagaimanakah akhir sebuah cerita (Nurgiyantoro, 2005:146).

Penokohan sering juga disamakan artinya dengan karakter dan perwatakan yang menunjuk pada penempatan tokohtokoh tertentu dengan watak-watak tertentu dalam sebuah cerita (Nurgiyantoro, 2005:165). Penokohan dibagi menjadi dua, yaitu tokoh utama dan tokoh tambahan. Tokoh utama adalah tokoh yang banyak diceritakan dalam novel yang bersangkutan, baik sebagai pelaku kejadian maupun yang dikenai kejadian. Tokoh tambahan adalah 
tokoh yang mendukung perwatakan tokoh utama (Nurgiyantoro, 2005:177).

Latar dibagi menjadi tiga, yaitu: (1) Latar tempat, menyaran pada lokasi terjadinya peristiwa yang diceritakan dalam sebuah karya fiksi. Penggunaan latar tempat dengan nama-nama tertentu mencerminkan sifat dan keadaan geografis tempat yang bersangkutan (Nurgiyantoro, 2005:227). (2) Latar waktu berhubungan dengan masalah kapan terjadinya peristiwa-peristiwa yang diceritakan dalam sebuah karya fiksi. Masalah tersebut biasanya dihubungkan dengan waktu faktual, waktu yang ada kaitannya atau dapat dikaitkan dengan peristiwa sejarah (Nurgiyantoro, 2005:230). (3) Latar sosial berhubungan dengan perilaku kehidupan sosial masyarakat di suatu tempat yang diceritakan dalam karya fiksi. Tata cara kehidupan masyarakat mencakup berbagai masalah ruang lingkup yang cukup kompleks, dapat berupa kebiasaan hidup, adat istiadat, keyakinan, pandangan hidup, cara berpikir dan bersikap, dan lain-lain yang tergolong latar spiritual. Selain itu, latar sosial juga berhubungan dengan status sosial tokoh yang bersangkutan (Nurgiyantoro, 2005:233-234).

Bahasan terakhir dalam penelitian ini adalah analisis mitos keris dalam aspek budaya, agama, dan pendidikan. Manusia dalam masyarakat dan lingkungan sebagai pendukung mitos berada dalam lingkup sosial budaya. Mereka senantiasa berusaha untuk memahami diri dan kedudukannya dalam alam semesta sebelum mereka menentukan sikap dan tindakan untuk mengembangkan kehidupannya dalam suatu masyarakat. Manusia menggunakan kemampuan akalnya berusaha memahami setiap gejala yang tampak maupun yang tidak tampak. Kendati demikian manusia sebagai makhluk yang memiliki akal dan pikiran tidak mampu untuk menjelaskan fenomena yang ada di sekitanya. Mitos yang tumbuh di masyarakat diyakini memiliki pesan. Walaupun pesan tersebut sulit diterima akal karena pada awalnya mitos terbentuk secara tidak rasional. Di sisi lain masyarakat mempercayai atau menerima pesan yang terkandung dalam mitos tanpa mempertanyakan secara kritikal. Bagi masyarakat, mitos berfungsi sebagai pernyataan tentang kenyataan yang tidak tampak secara kasat mata. Hal inilah yang tampak dalam novel Hunus. Dalam Kamus Besar Bahasa Indonesia (2008:214), budaya adalah pikiran, akal budi, adat istiadat, sesuatu mengenai kebudayaan yang sudah berkembang atau sesuatu yang sudah menjadi kebiasaan yang sudah sukar diubah. (2) Menurut Kamus Besar Bahasa Indonesia (2008:15), agama ialah ajaran atau sistem yang mengatur keimanan(kepercayaan) dan peribadatan kepada Tuhan Yang Mahakuasa serta kaidah yang berhubungan dengan pergaulan sesama manusia serta manusia dengan lingkungannya. (3) Menurut Kamus Besar Bahasa Indonesia (2008:326), pendidikan adalah proses perubahan sikap dan tata laku seseorang atau sekelompok orang dalam usaha mendewasakan manusia melalui upaya pengajaran dan latihan, proses, perbuatan, cara mendidik.

\section{Simpulan}

Berdasarkan analisis dalam bab-bab sebelumnya, penelitian ini diakhiri dengan simpulan sebagai berikut. Novel Hunus karya Sunaryono Basuki Ks, sebuah novel yang menceritakan kepercayaan tradisional (mitos) masyarakat Bali mengenai keris. Tony yang harus kehilangan beberapa orang terdekatnya secara turut-menurut di masa lalu ketika keris miliknya dihunus. Akhirnya ia bertemu dengan Wayan yang membantu untuk mendengarkan kegelisahannya serta berkenan 
mengembalikan kembali keris tersebut pada mantan bos Tony. Pada akhirnya, keris tersebut dikembalikan dan Tony hidup bahagia.

Tokoh utama adalah Anthony Wright. Sedangkan, tokoh tambahan adalah Anak Agung Ngurah Maharani, Wayan, Husni, dan Ida Bagus Sudiara.

Alur dalam novel Hunus disusun secara kronologis. Novel ini menggunakan alur mundur (flashback), Mulai dari tahapan awal, menjelaskan awal perkenalan Tony dengan Wayan. Tahap tengah merupakan tahap pemunculan konflik. Konflik berawal dari Tony yang tidak mempedulikan larangan Gung Ari mengenai menghunus keris. Gung Ari menyatakan jika keris dihunus pada waktu yang tidak tepat, akan menimbulkan malapetaka. Tony melawan, akibatnya satu persatu orang yang dicintainya meninggal setiap kali keris dihunus, yaitu David (teman Tony), Isabel (ibu Tony), Gung Ari (istri Tony), Cempaka (anak Tony), dan terakhir Bob (teman Tony). Tahap akhir sebagai tahap penyelesaian sebuah cerita. Tony akhirnya percaya pada kesaktian keris dengan mengembalikan keris pada pemiliknya. Tony pun menjalani kembali hidupnya dengan bahagia.

Novel Hunus berlatar di beberapa tempat yaitu di Indonesia dan Inggris. Latar waktu dalam novel Hunus tidak digambarkan dengan jelas oleh pengarang. Namun, secara implisit latar waktu pada novel ini ialah sekitar tahun 1990-an. Latar sosial dalam novel Hunus menggambarkan masyarakat Bali yang mempercayai adanya kesaktian keris. Novel Hunus menyajikan keadaan masyarakat yang terkenal dengan adat istiadatnya serta keyakinan tentang keris

Pada bahasan terakhir pada bab ini adalah mitos keris yang terdapat dalam novel Hunus dibahas berdasarkan teori sosiologi sastra. Kajian sosiologi sastra ini difokuskan pada tiga aspek, yaitu aspek budaya, aspek agama, dan pendidikan. Aspek budaya membahas upacara tumpek landep yang dilaksanakan masyarakat Bali. Dalam novel dijelaskan tata cara masyarakat Bali menyucikan benda pusaka dalam hal ini keris pada upacara Tumpek Landep. Selain dalam upacara tumpek landep, keris juga digunakan dalam upacara pernikahan dengan adat temanten Bali. Dalam dunia keris tidak sembarang orang bisa memiliki keris tersebut walaupun ia adalah keturunan dari pemilik keris. Hal ini dalam dunia keris disebut "jodoh keris". "Jodoh keris" sudah mengakar dalam masyarakat yang memiliki kepercayaan tentang kekuatan magis keris. Aspek magis tersebut berhubungan dengan identitas pemiliknya. Aspek agama membicarakan latar belakang agama para tokoh mempercayai mitos keris. Tony dengan prinsip agama bersifat pribadi memandang mitos keris hanya suatu dongeng atau takhyul yang akan berlaku pada masyarakat yang memercayainya. Kepercayaan Tony mengenai kesaktian keris timbul setelah menyaksikan sendiri kematian beberapa orang terdekatnya setiap kali keris dihunus. Sedangkan Gung Ari (istri Tony) beragama Hindu mempercayai mitos keris secara turun temurun berupa petuah maupun ritual tumpek landep yang harus diyakini. Aspek pendidikan membahas pendidikan yang didapatkan para tokoh mempengaruhi cara pandang terhadap mitos keris yang terjadi dalam konflik novel. Mendapatkan pendidikan formal yang sama, namun tokoh Gung Ari (istri Tony) memperoleh pendidikan informal dalam keluarganya mengenai mitos tentang keris. Berbanding terbalik dengan Tony yang hanya mendapatkan pendidikan formal. Tony jelas tidak mendapatkan pendidikan informal mengenai mitos, dikarenakan lumrahnya masyarakat barat tidak mempercayai eksistensi suatu mitos. Mereka 
berpandangan bahwa suatu mitos hanya berlaku bagi masyarakat yang mempercayainya, dan juga sebagian dari mereka menganggap mitos hanya sebuah takhyul. Mitos keris dalam novel Hunus mengajarkan bahwa kita harus menghargai setiap kepercayaan suatu masyarakat meskipun kita tidak lahir dan tumbuh dengan mitos tersebut.

\section{Daftar Pustaka}

Basuki, Sunaryono Ks. 1991. Hunus. Jakarta: Balai Pustaka.

Danandjaya, James. 1991. Folklor Indonesia: Ilmu gosip, dongeng, dan lain-lain. Jakarta: PT Pustaka Utama Grafiti.

Departemen Pendidikan Nasional. 2008. Kamus Besar Bahasa Indonesia. Edisi Keempat. Jakarta: PT Gramedia Pustaka.

Endraswara, Suwardi. 2008. Metodologi Penelitian Sastra. Yogyakarta: Media Pressindo.

Moleong, Lexy J. 1990. Metode Penelitian Kualitatif. Bandung: Remaja Rosdakarya.

Nurgiyantoro, Burhan. 2005. Teori Pengkajian Fiksi. Cetakan kelima. Yogyakarta: Gadjah Mada University Press.

Ratna, Nyoman Kutha. 2007. Teori, Metode, dan Teknik Penelitian Sastra. Yogyakarta: Pustaka Pelajar. 